\title{
Brevicoryne brassicae aphids interfere with transcriptome responses of Arabidopsis thaliana to feeding by Plutella xylostella caterpillars in a density-dependent manner
}

\author{
Anneke Kroes ${ }^{1}\left(\mathbb{D} \cdot\right.$ Colette Broekgaarden $^{2} \cdot$ Marcos Castellanos Uribe $^{3} \cdot$ Sean May $^{3} \cdot$ \\ Joop J. A. van Loon ${ }^{1} \cdot$ Marcel Dicke ${ }^{1}$
}

Received: 10 July 2016 / Accepted: 16 October 2016 / Published online: 22 October 2016

(c) The Author(s) 2016. This article is published with open access at Springerlink.com

\begin{abstract}
Plants are commonly attacked by multiple herbivorous species. Yet, little is known about transcriptional patterns underlying plant responses to multiple insect attackers feeding simultaneously. Here, we assessed transcriptomic responses of Arabidopsis thaliana plants to simultaneous feeding by Plutella xylostella caterpillars and Brevicoryne brassicae aphids in comparison to plants infested by $P$. xylostella caterpillars alone, using microarray analysis. We particularly investigated how aphid feeding interferes with the transcriptomic response to $P$. xylostella caterpillars and whether this interference is dependent on aphid density and time since aphid attack. Various JAresponsive genes were up-regulated in response to feeding by $P$. xylostella caterpillars. The additional presence of aphids, both at low and high densities, clearly affected the transcriptional plant response to caterpillars. Interestingly, some important modulators of plant defense signalling, including $W R K Y$ transcription factor genes and ABA-dependent genes, were differentially induced in
\end{abstract}

Communicated by Ian Kaplan.

Electronic supplementary material The online version of this article (doi:10.1007/s00442-016-3758-3) contains supplementary material, which is available to authorized users.

Anneke Kroes

annekekroes@hotmail.com

1 Laboratory of Entomology, Wageningen University, P.O. Box 16, 6700 AA Wageningen, The Netherlands

2 Plant-Microbe Interactions, Department of Biology, Faculty of Science, Utrecht University, 3508 TB Utrecht, The Netherlands

3 Nottingham Arabidopsis Stock Centre, University of Nottingham, School of Biosciences, Loughborough LE12 5RD, UK response to simultaneous aphid feeding at low or high density compared with responses to $P$. xylostella caterpillars feeding alone. Furthermore, aphids affected the $P$. xylostella-induced transcriptomic response in a densitydependent manner, which caused an acceleration in plant response against dual insect attack at high aphid density compared to dual insect attack at low aphid density. In conclusion, our study provides evidence that aphids influence the caterpillar-induced transcriptional response of $A$. thaliana in a density-dependent manner. It highlights the importance of addressing insect density to understand how plant responses to single attackers interfere with responses to other attackers and thus underlines the importance of the dynamics of transcriptional plant responses to multiple herbivory.

Keywords Feeding guilds · Microarray $\cdot$ Multiple herbivory $\cdot$ Plant defense $\cdot$ Transcriptome

\section{Introduction}

Throughout the growing season, plants are commonly attacked by multiple herbivorous species. The responses of plants to one specific herbivore may impact the performance of other insects feeding on the same host plant (Rodriguez-Saona et al. 2010; Soler et al. 2012; Zhang et al. 2013; Stam et al. 2014). Interestingly, defenses induced in response to multiple insect feeding (Rodriguez-Saona et al. 2010; Tzin et al. 2015b; Onkokesung et al. 2016), can have positive or negative effects on the performance of one of the attacking herbivores (Soler et al. 2012; Ali et al. 2014; Li et al. 2014; Kroes et al. 2015). For example, while oleander aphids (Aphis nerii) developed more slowly on milkweed plants (Asclepias syriaca) previously infested by 
monarch caterpillars (Danaus plexippus) (Ali et al. 2014), Brevicoryne brassicae aphids developed faster on cabbage plants previously infested by Pieris brassicae caterpillars (Soler et al. 2012). Studies on the molecular aspects of plant-mediated interactions among multiple insects have shown that transcriptomic responses to multiple attacks are clearly different from responses to attacks by individual insects (Voelckel and Baldwin 2004; Rodriguez-Saona et al. 2010; Zhang et al. 2013; Coolen et al. 2016; Davila Olivas et al. 2016). For instance, tomato plants (Solanum lycopersicum) exhibited a different transcriptomic response to simultaneous attack by Spodoptera exigua caterpillars and Macrosiphum euphorbiae aphids than to attack by the caterpillar or aphid alone (Rodriguez-Saona et al. 2010). This study also demonstrated that aphid feeding suppressed the expression of caterpillar-induced genes and, vice versa, caterpillar feeding down-regulated the expression of genes up-regulated by aphids (Rodriguez-Saona et al. 2010). In dually infested Arabidopsis thaliana plants, the phloemfeeding whitefly Bemisia tabaci suppressed the expression of genes up-regulated by Plutella xylostella caterpillars (Zhang et al. 2013).

The differential effects of multiple insect feeding on induced defenses may not only be explained by species differences, but may also be dependent on insect density (Zhang et al. 2009; Kroes et al. 2015; Stewart et al. 2016). For instance, B. brassicae aphids had differential plantmediated effects on the performance of $P$. xylostella caterpillars: at low aphid density caterpillar growth rate was enhanced while it was reduced at high aphid density (Kroes et al. 2015). Therefore, investigating effects of insect density on plant defense responses can provide novel insights in plant-mediated interactions between multiple attacking insects. Investigating how insects belonging to different feeding guilds affect each other's individually induced plant transcriptional response, while including effects of insect density, is an important step towards unravelling plant responses to simultaneously feeding herbivores.

The phytohormones jasmonic acid (JA) and salicylic acid (SA) have been recognized to play key roles, with ethylene (ET) and abscisic acid (ABA) as co-regulators, in mediating plant defense responses against herbivorous insects (Erb et al. 2012; Broekgaarden et al. 2015). The different phytohormone signalling pathways operate in an interacting network allowing the plant to activate an adequate defense response depending on the feeding guild and species identity of the attacking insect (De Vos et al. 2005; Bidart-Bouzat and Kliebenstein 2011; Robert-Seilaniantz et al. 2011; Derksen et al. 2013; Pieterse et al. 2012; Appel et al. 2014). Specific nodes in this network, such as the transcriptional regulators WRKY70 and ORA59, integrate phytohormonal signalling and regulate plant defenses in response to herbivory (Caarls et al. 2015).
Plant defenses induced by caterpillars are mainly regulated by the phytohormone jasmonic acid (JA) and its derivatives such as methyl jasmonate (MeJA) and jasmonic acid-isoleucine (JA-Ile) (Thaler et al. 2002; Turner et al. 2002; Halitschke and Baldwin 2003; Koo and Howe 2009; Verhage et al. 2011; Rehrig et al. 2014). JA-Ile binds to the CORONATINE INSENSITIVE 1 (COI1) receptor thereby mediating the degradation of JAZ repressor proteins (Thines et al. 2007). In the absence of JA, these JAZ proteins bind to the transcription factor MYC2 that consequently prevents the regulation of JA-responsive genes such as PLANT DEFENSIN 1.2 (PDF1.2) and VEGETATIVE STORAGE PROTEIN 2 (VSP2) (Lorenzo et al. 2004; Memelink 2009; Kazan and Manners 2013). The JA-signalling pathway consists of two interconnected branches, either regulated by MYC2 or ERF (Lorenzo et al. 2003), that cross-communicate with the ET and ABA pathways depending on the plant attacker (Lorenzo and Solano 2005; Pieterse et al. 2012; Kazan and Manners 2013). MYC2 regulates the biosynthesis of defensive secondary metabolites such as glucosinolates (Dombrecht et al. 2007; Kazan and Manners 2013) and terpenoids (Hong et al. 2012; Kazan and Manners 2013). Different from leaf chewing by caterpillars, aphids feed on the plant's phloem by inserting their stylets into the sieve elements (De Vos et al. 2007; Stam et al. 2014). Regulation of plant defenses to aphid feeding is mainly mediated by SA, but involvement of JA and ET has also been reported (Moran et al. 2002; De Vos et al. 2005; Couldridge et al. 2007; Kusnierczyk et al. 2008; Barah et al. 2013; Appel et al. 2014; Hillwig et al. 2016).

Defense mechanisms and the underlying phytohormonal signalling have been intensively studied for A. thaliana in combination with herbivorous insects from the two main insect feeding guilds, i.e. leaf chewers and phloem feeders. Defense responses induced by leaf chewers such as $P$. xylostella caterpillars mainly involve the activation of JA-regulated genes (Stotz et al. 2000; Ehlting et al. 2008; Herde et al. 2008; Bidart-Bouzat and Kliebenstein 2011; Zhang et al. 2013; Kroes et al. 2015), while phloem feeders such as $B$. brassicae aphids enhance the expression of genes involved in SA-dependent defenses (Moran et al. 2002; Kusnierczyk et al. 2008; Barah et al. 2013). In addition, Barah et al. (2013) found B. brassicae-induced expression of genes related to the biosynthesis of tryptophan-derived secondary metabolites, the ET signalling pathway, as well as to cell wall metabolism (Kusnierczyk et al. 2008). Moreover, also JA-regulated defenses have been found to be involved in responses to aphid feeding (Moran et al. 2002; Kusnierczyk et al. 2008; Morkunas et al. 2011). In the present study, we investigated how phloem feeding by $B$. brassicae aphids affects the transcriptional response of $A$. thaliana to leaf-chewing P. xylostella caterpillars. This study builds upon our recent finding 
that $B$. brassicae aphids feeding on A. thaliana plants at low or high aphid densities differentially affect defense of the plants to P. xylostella and that this is mediated by JA and SA signalling (Kroes et al. 2015). Here, we compared transcriptomic responses of A. thaliana plants to simultaneous feeding by $P$. xylostella caterpillars and B. brassicae aphids to transcriptomic responses of plants to infestation by $P$. xylostella caterpillars alone. We particularly addressed the question whether the transcriptomic response to simultaneous attack by aphids and caterpillars is affected by aphid density. To study density-dependent effects on transcriptomic responses, plants were infested with a low or high aphid density according to the same methods as we used previously (Kroes et al. 2015). In addition, transcriptional responses were studied at two time points to study the dynamics of simultaneous herbivory.

\section{Materials and methods}

\section{Plant growth conditions}

Seeds of Arabidopsis thaliana accession Columbia-0 (Col$0)$ were sown in autoclaved $\left(80{ }^{\circ} \mathrm{C}\right.$ for $\left.4 \mathrm{~h}\right)$ potting soil (Lentse potgrond, Lent, The Netherlands). Plants were cultivated in a growth chamber at $21 \pm 2{ }^{\circ} \mathrm{C}$ under an 8L:16D cycle $\left[200 \mu \mathrm{mol} \mathrm{m} \mathrm{m}^{-2} \mathrm{~s}^{-1}\right.$ photosynthetically active radiation (PAR) light intensity] and $60 \pm 10 \%$ relative humidity (RH). Two-week-old seedlings were transferred to individual pots ( $5 \mathrm{~cm}$ diameter) containing similar soil. Plants were watered three times per week. Five-week-old plants were exposed to different insect-infestation treatments. During the experiments, all plants remained in the vegetative state.

\section{Insects}

Both the Cabbage aphid, B. brassicae L. (Hemiptera: Aphididae), and the Diamondback moth, P. xylostella L. (Lepidoptera: Yponomeutidae), were reared on Brussels sprouts plants (Brassica oleracea var gemmifera cv Cyrus) at $22 \pm 1{ }^{\circ} \mathrm{C}, 50-70 \% \mathrm{RH}, 16 \mathrm{~L}: 8 \mathrm{D}$ cycle.

\section{Insect infestation treatments}

Plants were infested with (1) two second-instar (L2) caterpillars (indicated as single infestation); (2) simultaneously infested with two L2 caterpillars plus a low density of five adult aphids (abbreviated as Dual LD for Dual Low Density); (3) simultaneously infested with two L2 caterpillars plus a high density of 25 adult aphids (abbreviated as Dual HD for Dual High Density), or (4) left uninfested (indicated as control). Insects were allowed to feed freely on the plants.
Individual plants were placed in a plastic container (diameter $8 \mathrm{~cm} \times$ height $14 \mathrm{~cm}$ ), covered with gauze cloth and closed with elastic bands. Containers were randomly distributed in a tray (12-15 containers per tray). Trays were placed in a growth chamber with a $16 \mathrm{~L}: 8 \mathrm{D}$ cycle [200 $\mu \mathrm{mol} \mathrm{m}^{-2} \mathrm{~s}^{-1} \mathrm{PAR}$ ], at $21 \pm 2{ }^{\circ} \mathrm{C}$ and $50-70 \% \mathrm{RH}$.

Leaves damaged by insect feeding or control leaves from uninfested plants were collected after 24 or $48 \mathrm{~h}$ of infestation. The experiment was performed in two rounds starting on two successive days (Feb 2015). For each treatment and time point, four biological replicates were obtained by performing two biological replicates per round. One biological replicate consisted of six leaves pooled from three different plants. For each time point, a different set of plants was used. Insects were removed from the leaves before harvesting. Leaf samples were flash-frozen in liquid nitrogen and stored at $-80^{\circ} \mathrm{C}$ prior to analysis.

\section{RNA extraction and microarray hybridization}

Total RNA was extracted from finely ground frozen leaf tissue using the RNeasy Plant Mini Kit (Qiagen, Hilden, Germany). RNA samples were treated with DNase (Qiagen, Hilden, Germany). The concentration and purity of RNA was determined by spectrophotometry and integrity was confirmed using an Agilent 2100 Bioanalyzer with the RNA 6000 Nano Kit (Agilent Technologies, Palo Alto, CA, USA). Whole-genome transcriptome analysis was conducted by hybridizing four biological samples of total RNA per treatment to Affymetrix Arabidopsis Gene 1.1 ST Array Strips (Affymetrix, Santa Clara, CA, USA).

\section{Microarray data analysis}

The raw data files (CEL files) were normalized using the Robust Multi-array Average (RMA) background correction with quantile normalization, $\log _{2}$ transformation and mean probe-set summarization with adjustment for GC content. Normalized gene expression data obtained from the microarray experiments were initially statistically analysed with oneway and two-way ANOVA using the software TIGR MeV version 4.9 (Saeed et al. 2003, 2006) to study the effects of treatment, time point and their interaction on gene expression levels, with $\alpha=0.05$. Expression ratios of the genes significantly differentially expressed between the four treatment groups (Control, P. xylostella, Dual LD and Dual HD) and time points ( 24 and $48 \mathrm{~h}$ ) were then used for further analysis.

Partial least squares discriminant analysis (PLS-DA) data analysis

Changes in the expression pattern of genes that were significantly different between treatments were analysed using projection to latent structures discriminant analysis 
(PLS-DA; Eriksson et al. 2013) using SIMCA-P+ version 14.0 statistical software (Umetrics AB, Umeå, Sweden). The analysis determines whether samples from different treatment groups can be separated on the basis of differences in their gene expression patterns. The results of the analysis are visualized in score plots. The score plot identifies patterns that discriminate the treatments according to model components of PLS-DA. The quality of each OPLSDA model was evaluated using the parameter $R^{2}$ (goodness of fit) and $Q^{2}$ (predictive value) (Eriksson et al. 2013).

\section{Differentially expressed genes}

Differentially expressed genes (DEGs) were identified per time point for the different single and dual-infestation treatments. Differential gene expression in caterpillar- or dualinfested plants was determined compared to expression in uninfested control plants, with gene expression in dually infested plants additionally being compared to expression in P. xylostella-infested plants.

Genes were considered to be differentially regulated in a given pair of treatments if a $t$ test demonstrated a significant result at $P<0.05$ (accepting a false discovery rate of up to 0.2 ; Ehlting et al. 2008) and a $\log _{2}$-fold change of $\leq-1$ or $\geq 1$ (TIGR MeV v4.9).

\section{Functional enrichment}

Identification and enrichment of DEGs within functional gene ontology (GO) terms for biological processes was done using the online tool provided by DAVID Bioinformatics Resources (http://david.abcc.ncifcrf.gov/; Huang et al. 2009). Only enrichment groups with an enrichment score $\geq 1.3$ were examined (Huang et al. 2009). Genes were considered statistically enriched if Fisher's exact test (EASE score) resulted in $P<0.05$ and if the Benjamini-Hochberg correction for multiple comparisons returned $P<0.05$.

\section{Hierarchical clustering}

Genes differentially expressed at 24 and $48 \mathrm{~h}$ after single $P$. xylostella or dual P. xylostella and B. brassicae infestation at low or high aphid density (measured relative to uninfested control samples) were organized further by hierarchical clustering. Hierarchical clustering analysis was performed with the Spearman rank correlation using average linkage in the software TIGR MeV version 4.9.

\section{Validation of microarray analysis by quantitative real-time PCR}

cDNA was synthesized from the same RNA $(1 \mu \mathrm{g})$ isolated for the microarray hybridization as described in the 'RNA extraction and microarray hybridization' section using iScript cDNA synthesis Kit (Bio-Rad). Transcript levels of the genes TERPENE SYNTHASE 04 (TPSO4) (At1g61120) (Snoeren et al. 2010), VEGETATIVE STORAGE PROTEIN 2 (VSP2) (At5g24770) (Anderson et al. 2004) and PLANT DEFENSIN 1.2 (PDF1.2) (At5g44420) (Anderson et al. 2004) and the reference gene ELONGATION FACTOR $1 \alpha$ (EF1- $\alpha)$ (At5g60390) (Remans et al. 2008) were quantified. Efficiency of each primer was determined before qRT-PCR analysis. Quantitative RT-PCR analysis was performed in a CFX96 Touch ${ }^{\mathrm{TM}}$ Real-Time PCR Detection System (Bio-Rad). Each reaction was performed in a total volume of $25 \mu \mathrm{l}$ containing $12.5 \mu \mathrm{l}$ SYBR Green Supermix (BioRad), $5 \mu \mathrm{l}$ cDNA and $1 \mu \mathrm{l}$ of $10 \mu \mathrm{M}$ forward and reverse gene-specific primer pair. For each reaction, two technical replicates were performed and average values were used in the analyses. The following thermal profile was used: $3 \mathrm{~min}$ $95{ }^{\circ} \mathrm{C}$, followed by 40 cycles of $15 \mathrm{~s}$ at $95^{\circ} \mathrm{C}$, and $45 \mathrm{~s}$ at $60{ }^{\circ} \mathrm{C}$.

Relative expression for each tested gene was calculated by using the $2^{-\Delta \Delta \mathrm{Ct}}$ method (Livak and Schmittgen 2001) and subsequently $\log _{2}$ transformed. Relative expression levels of TPSO4, VSP2 and PDF1.2 were compared to their respective $\log _{2}$-expression ratios found using microarray analysis (Online Resource 1).

\section{Results}

Transcriptomic changes in plants in response to feeding by $P$. xylostella alone or by both $P$. xylostella and $B$. brassicae

Transcriptional profiles in A. thaliana after $24 \mathrm{~h}$ (Fig. 1a) and $48 \mathrm{~h}$ (Fig. 1b) to feeding by P. xylostella only, or dual infestation by $P$. xylostella plus $B$. brassicae at low and high density and without infestation were analysed by PLSDA using expression levels of all genes that showed significant differences in expression level between treatments (based on one-way ANOVA).

At $24 \mathrm{~h}$, the first two significant PLS components explain 49 and $12 \%$ of the total variance, respectively (Fig. 1a). The first component shows a clear separation between transcriptional profiles of dually infested plants at high density (Dual HD) versus the other three treatments, while the second component separated the profiles based on the presence or absence of herbivores.

At $48 \mathrm{~h}$, the first two significant PLS components explain 61 and $11 \%$ of the total variance, respectively (Fig. 1b). As was found for the 24-h time point, the first component shows a clear separation of transcriptional profiles between Dual HD plants versus the other three treatments, while the second component separates the profiles based on the 

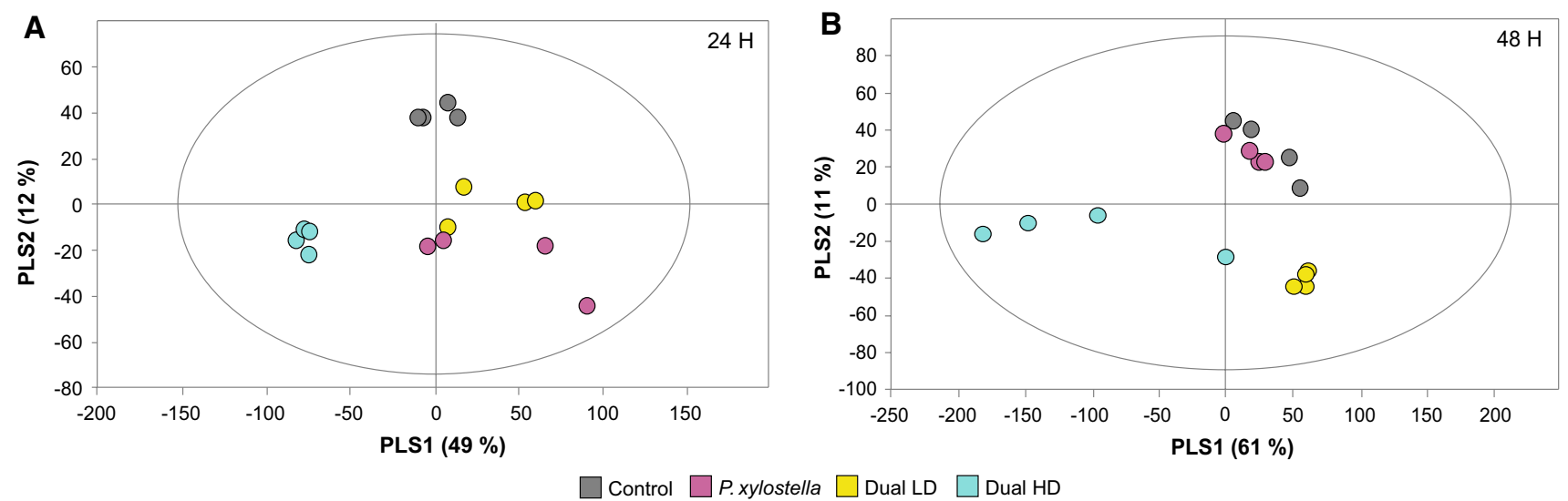

Fig. 1 Partial least squares discriminant analysis (PLS-DA) of gene expression levels in A. thaliana at $24 \mathrm{~h} \mathrm{(a)} \mathrm{and} 48 \mathrm{~h} \mathrm{(b)}$ after single P. xylostella, dual P. xylostella and B. brassicae and without infestation (control). Plants were infested with either a low (LD, 5 aphids per plant) or high (HD, 25 aphids per plant) density of $\mathrm{B}$. brassicae aphids. The PLS-DA resulted in two models with six $(24 \mathrm{~h}$;

presence of aphids. Interestingly, when comparing the position of $P$. xylostella-infested samples between the PLSDA models of 24 and $48 \mathrm{~h}$, the gene expression profiles in response to caterpillar feeding differs more strongly from that of non-infested plants after $24 \mathrm{~h}$, whereas the profiles have converged after $48 \mathrm{~h}$.

\section{Differentially expressed transcripts in response to $P$. xylostella alone or in response to both $P$. xylostella and $B$. brassicae}

To identify differentially expressed genes (DEGs) in $A$. thaliana in response to caterpillars feeding alone or simultaneous feeding of caterpillars and aphids, we compared the expression of genes in uninfested control plants to that in plants treated with herbivores.

The number of DEGs induced in response to feeding by $P$. xylostella was larger than the number of repressed genes (Fig. 2a). However, the number of induced genes decreased over time. When $P$. xylostella caterpillars were feeding simultaneously with $B$. brassicae aphids, the number of DEGs was higher after 24 and $48 \mathrm{~h}$ compared to the response to caterpillars feeding alone (Fig. 2a). Interestingly, there was an aphid-density effect on the number of DEGs over time (Fig. 2a). After 24-h dual HD plants showed a larger number of DEGs compared to dual aphid and caterpillar infestation at low aphid density (Dual LD). More repressed DEGs were found after $48 \mathrm{~h}$ in Dual HD plants, while the number of induced DEGs was comparable to that in Dual LD plants after $48 \mathrm{~h}$ (Fig. 2a).

In total, only $10 \%$ of induced DEGs were shared among the different treatments at $24 \mathrm{~h}$ (Fig. 2b). Moreover, the
$R^{2} X=0.80, R^{2} Y=0.99$ and $\left.Q^{2}=0.92\right)$ and five ( $48 \mathrm{~h} ; R^{2} X=0.83$, $R^{2} Y=0.98$ and $Q^{2}=0.87$ ) significant components, respectively. The score plots of the treatment samples at 24 and $48 \mathrm{~h}$, with the percentage of explained variation in parentheses, is shown. The ellipse in the score plots defines the Hotelling's T2 confidence region (95\%)

treatments only shared $1 \%$ of their induced genes at $48 \mathrm{~h}$ (Fig. 2b). Thus, A. thaliana responses to aphids and caterpillars feeding simultaneously or caterpillars feeding alone are highly dissimilar.

Almost all DEGs in response to $P$. xylostella feeding were shared with DEGs found in Dual LD or Dual HD plants at both 24 and $48 \mathrm{~h}$ (Fig. 2b). Respectively, $41 \%$ of up-regulated genes in response to Dual LD and $12 \%$ of upregulated genes in response to Dual HD were shared with DEGs up-regulated by $P$. xylostella feeding at $24 \mathrm{~h}$. At $48 \mathrm{~h}$, a low proportion of up-regulated DEGs $(<7 \%)$ in response to Dual LD and Dual HD were shared with DEGs up-regulated in response to P. xylostella feeding. Thus, the presence of aphids on P. xylostella-infested plants increased the number of DEGs, while the number of DEGs in response to P. xylostella feeding did not change.

In conclusion, dual herbivory by aphids and caterpillars resulted in different transcriptional responses compared to those induced by $P$. xylostella caterpillars feeding alone. Furthermore, specificity in transcriptional responses to simultaneous feeding of both herbivores or caterpillars feeding alone increased over time.

\section{Gene clustering and GO terms}

To identify biological functions of the DEGs we assigned GO terms for biological processes and performed a functional clustering analysis using the DAVID Functional Clustering Tool (Online Resource 2 and 3).

For P. xylostella-induced genes (at both 24 and $48 \mathrm{~h}$ ), the clusters mainly relate to responses to biotic stress, including pathogen infection and wounding, and jasmonic acid stimuli. 


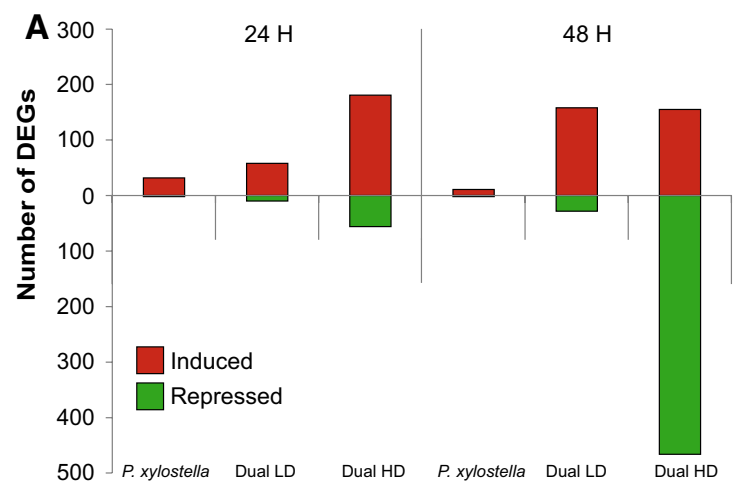

Fig. 2 Differentially expressed genes (DEGs) (a) and Venn diagram of number of DEGs (b) in $A$. thaliana at 24 and $48 \mathrm{~h}$ after single $P$. xylostella, dual $P$. xylostella and $B$. brassicae and without infestation (control). Plants were infested with either a low (LD, 5 aphids per plant) or high (HD, 25 aphids per plant) density of B. brassicae aphids. Number of DEGs in P. xylostella-infested, Dual LD and Dual

However, when caterpillars feed simultaneously with aphids at either of the two densities, clusters also associated with metabolism of organic acids, fatty acids and lipids.

After $48 \mathrm{~h}$ in Dual HD plants, repressed DEGs mainly clustered in classes that relate to photosynthesis and carbohydrate metabolism, including genes encoding for thioredoxins and glutaredoxins, Photosystem (PS I and II) proteins, PsbP proteins and proteins involved in the glycolysis pathway.

\section{Differentially expressed transcripts under dual herbivory at low or high aphid density}

To investigate how aphid density influences effects on transcriptional responses to caterpillar herbivory, differential gene expression was determined in comparison to expression in caterpillar-infested plants. We examined differences and overlap in DEGs compared to caterpillar-only treatment between Dual LD plants on the one hand and Dual HD plants on the other hand, both when the plants had been exposed to herbivory during 24 and $48 \mathrm{~h}$ (Fig. 3a, b).

There was no effect of a low aphid density on DEGs compared to caterpillar-only treatment after $24 \mathrm{~h}$ (Fig. 3a). However, a low aphid density caused changes in responses after $48 \mathrm{~h}$ (Fig. 3b). At $48 \mathrm{~h}$, a total of 87 up-regulated and 77 down-regulated DEGs, compared to caterpillar-only treatment were found in Dual LD plants. Of these DEGs, only $2 \%$ up- and down-regulated genes were shared with DEGs in Dual HD plants.

A total of 236 up-regulated DEGs after $24 \mathrm{~h}$ and 113 up-regulated DEGs after $48 \mathrm{~h}$, in comparison to caterpillaronly treatment, respectively, were found in Dual HD plants. In addition, 121 and 360 DEGs were down-regulated after 24 and $48 \mathrm{~h}$, respectively.
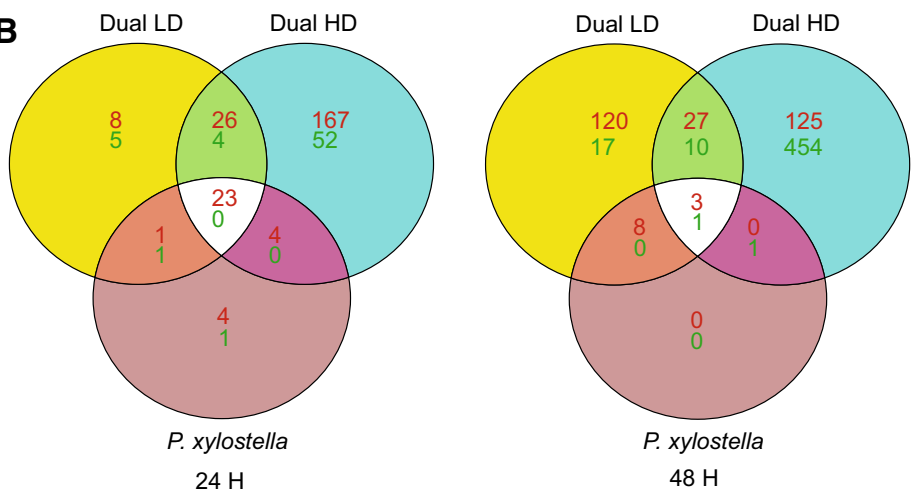

HD plants were compared with non-infested control plants. Red bars or numbers indicate up-regulated genes, while green bars or numbers represent down-regulated genes. Genes were considered to be differentially expressed if they met the criteria of $\log _{2}$-fold change $\leq-1$ or $\geq 1$ and a $t$ test $P$ value $<0.05$

In conclusion, when investigating how aphid density influences differential expression compared to caterpillaronly treatment between Dual LD and Dual HD after $48 \mathrm{~h}$, DEGs have very little overlap which indicates that DEGs are highly density-specific.

\section{Gene clustering and GO terms}

To identify biological functions of these genes, we assigned GO terms for biological processes and performed a functional clustering analysis using the DAVID Functional Clustering Tool (Online Resource 2 and 3).

After $48 \mathrm{~h}$ in Dual LD plants, up-regulated genes were associated with defense, cell death and auxin signalling. Repressed genes could not be clustered.

In Dual HD plants after $24 \mathrm{~h}$, up-regulated genes in comparison to caterpillar-only treatment were associated with transcriptional responses to hormone signalling (ABA- and auxin-activated signalling pathways) and carbohydrate metabolism. Repressed genes could not be clustered. At $48 \mathrm{~h}$, up-regulated genes could not be clustered. For repressed genes, clusters relate to carbohydrate metabolism, photosynthesis, responses to bacterium (several $W R K Y$ transcription factor genes) and biogenesis of cellular components.

\section{Clustering of gene expression levels}

We compared gene expression patterns of A. thaliana in response to feeding by $P$. xylostella caterpillars alone and simultaneous feeding by caterpillars and aphids at two different densities to further investigate the effect of simultaneous aphid feeding and aphid density on responses to caterpillars. 


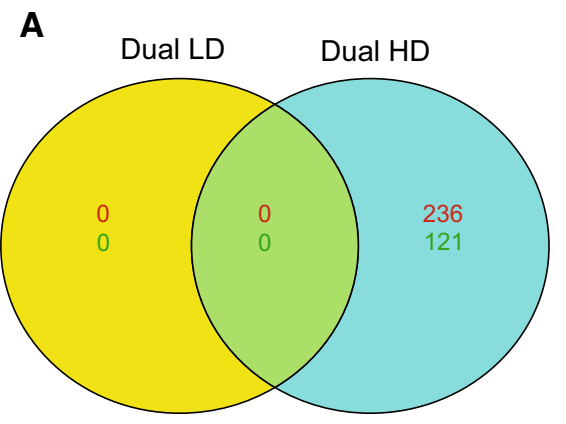

$24 \mathrm{H}$

Fig. 3 Venn diagram representing numbers of genes differentially expressed (DEGs) in A. thaliana at $24 \mathrm{~h}$ (a) and $48 \mathrm{~h} \mathrm{(b)} \mathrm{after} \mathrm{sin-}$ gle $P$. xylostella and dual infestation by $P$. xylostella plus $B$. brassicae. Plants were infested with either a low (LD, 5 aphids per plant) or high (HD, 25 aphids per plant) density of B. brassicae aphids. Number of DEGs specifically expressed or co-expressed in the Dual

\section{Clustering after 24 h of herbivory (based on one-way ANOVA)}

The cluster analysis shows similarities in gene expression levels in response to $P$. xylostella feeding alone and to Dual LD because both treatments cluster together and are separate from gene expression levels in response to Dual HD (Online Resource 4).

Cluster 5 is clearly different across treatments and consists of 111 genes that were more repressed in response to $P$. xylostella feeding and to Dual LD compared to Dual HD (Fig. 4). Cluster 5 contains genes involved in defense responses (MES7, PDF1.2B, PDF1.2, CCR2, PGIP2, ERD5), in responses to phytohormones (TTL3, ACR4, BT4, $P Y L 4, P Y L 5)$ and genes associated with cell wall remodelling (PME3, EXT3, FLA13, AGP16) (Online Resource 5A).

\section{Clustering after 48 h of herbivory (based on one-way ANOVA)}

Gene expression levels in response to $P$. xylostella feeding alone and to Dual HD cluster separately from those in response to Dual LD. This result shows that aphid density affects gene expression pattern and responses induced by caterpillar feeding are more similar to those induced by Dual HD (Online Resource 6).

For example, cluster 2 consists of genes that are more repressed in response to Dual HD and P. xylostella feeding compared to Dual LD (Fig. 5). Cluster 2 consists of 343 genes including genes involved in plant defense signalling (such as genes encoding TIFY protein family, RIPK, hevein-like protein, GLR3.4, MYB domain proteins and peroxidases), responses to phytohormones (such as genes involved in ABA, auxin and SA signalling), and

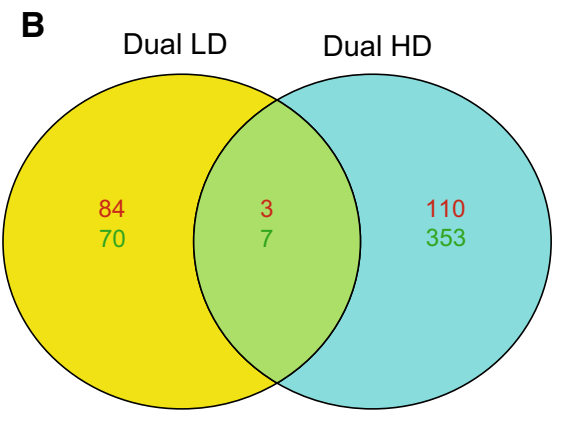

$48 \mathrm{H}$

LD and Dual HD treatments were compared with single $P$. xylostella infestation. Numbers in red indicate up-regulated genes, while numbers in green represent down-regulated genes. Genes were considered differentially expressed if they met the criteria of $\log _{2}$-fold change $\leq-1$ or $\geq 1$ and a $t$ test $P$ value $<0.05$

photosynthesis (such as genes encoding for thioredoxins and glutaredoxins, Photosystem (PS I and II) proteins, PsbP proteins and proteins involved in the glycolysis pathway) (Online Resource 5B). In addition, cluster 2 consists of genes involved in JA-mediated induced plant defenses (CHL1, JAZ9, JR1, NATA1, CORI3, JAZ1, PR4, JAZ2, PGIP2, AOC2, PDF1.2b, MES18) and genes involved in the biosynthesis of isopentenyl diphosphate and carotenoid (terpenoid metabolic processes) (Online Resource 5B). However, cluster 6 consists of 86 genes that were more induced in response to feeding by $P$. xylostella caterpillars and to Dual HD compared to Dual LD (Fig. 5). Cluster 6 contains genes involved in secondary metabolism (CYP706A2, CYP71B8, CYP710A3), responses to phytohormones (ethylene and auxin response factors) and genes encoding transcription factors (such as MADS-box and NAC domain proteins) which are involved in controlling all major aspects of development and hormone signalling (Online Resource 5B).

\section{Clustering over time (based on two-way ANOVA analysis)}

When gene expression levels were clustered by time point and treatment, responses induced by Dual LD during $48 \mathrm{~h}$ and Dual HD during $24 \mathrm{~h}$ clustered together, indicating that insects attacking at high densities cause an acceleration in plant responses compared to insects attacking at low density (Online Resource 7). Moreover, plants with Dual LD treatment during $24 \mathrm{~h}$ and plants with Dual HD treatment during $48 \mathrm{~h}$ clustered together, suggesting that responses to Dual HD after $48 \mathrm{~h}$ diminish to levels found after $24 \mathrm{~h}$ of Dual LD (Online Resource 7). However, responses to dual infestations at both densities after 24 and $48 \mathrm{~h}$, cluster separately from responses to dual infestations at low and high 


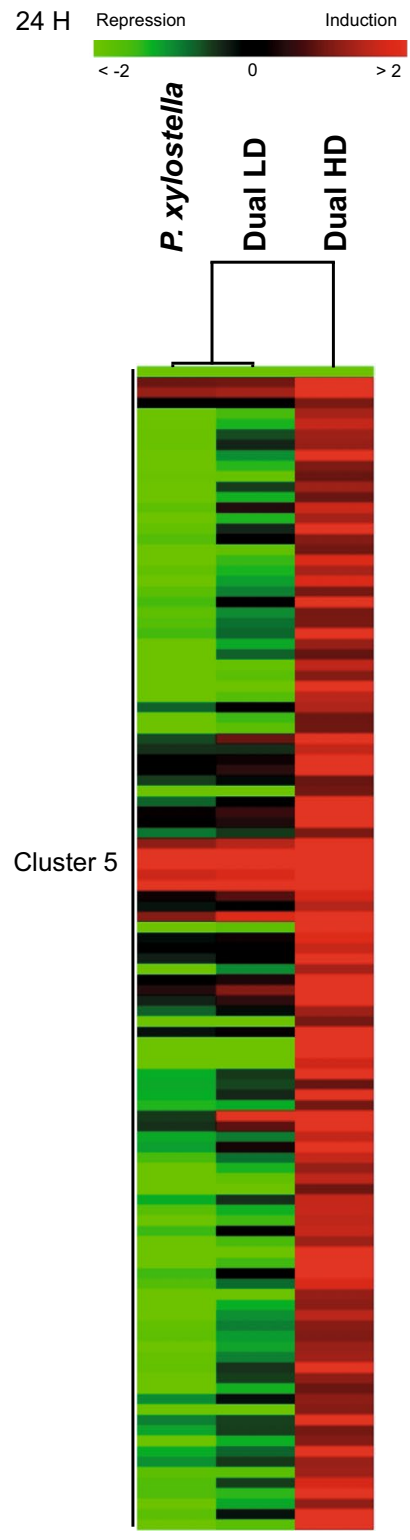

Fig. 4 Heat map showing average $\log _{2}$-fold change ratios (measured relative to non-infested control samples) of genes expressed in A. thaliana at $24 \mathrm{~h}$ after single P. xylostella or dual P. xylostella and $B$. brassicae infestation. Plants were infested with either a low (LD) or high (HD) density of $B$. brassicae aphids. Hierarchical clustering (HCL) was performed using Spearman correlation with average linkage clustering. Red indicates up-regulated genes, while green shows down-regulated genes. Black represents no change in expression. Each row in the columns corresponds to a single gene. Cluster analysis is shown for cluster 5

aphid density after 48 and $24 \mathrm{~h}$, respectively. This indicates that responses between the two time points are distinctly different (Online Resource 7).

For instance, in cluster 7, 150 genes were found that were more up-regulated by caterpillar feeding during 24 and $48 \mathrm{~h}$, Dual LD during $24 \mathrm{~h}$ and Dual HD during $48 \mathrm{~h}$ compared to the other treatments (Fig. 6). Several regulatory genes involved in defense responses and disease resistance (WRKY49, WRKY74, WRKY64), genes encoding MYB domain proteins and genes involved in secondary metabolism (CYP706A2, CYP71B8, CYP710A3, CYP71A28) belong to this cluster (Online Resource $5 \mathrm{C}$ ). In addition, cluster 7 consists of genes encoding transcription factors such as MADS-box, genes involved in defense responses (such as PROPEP3, MLO5, MLP329, FRK1 and LRC29, $L R C 17, L R C 37)$ and phytohormone-mediated signalling (such as ERF115, EIL2 and ARF23) (Online Resource 5C).

\section{Discussion}

Plants activate a complex array of defense reactions in response to feeding by insect herbivores (Kessler and Baldwin 2002; Mithofer and Boland 2012). Plants respond differently to leaf-chewing and piercing-sucking insects (De Vos et al. 2005; Bidart-Bouzat and Kliebenstein 2011; Appel et al. 2014). Here, we add to this knowledge by showing that herbivore density is an important modulator of such specific transcriptional responses of plants.

Studying the plant-mediated interactive effects of two insect attackers belonging to different feeding guilds can provide novel insights into the molecular aspects of plantmediated interactions among multiple insects. In the present microarray analysis, we found differences in gene expression in A. thaliana plants induced by $P$. xylostella caterpillars alone compared to infestation by a combination of $P$. xylostella caterpillars and $B$. brassicae aphids (Figs. 1, 2). Only a few studies have investigated the molecular aspects of plant-mediated interactions among multiple insects (Voelckel and Baldwin 2004; Rodriguez-Saona et al. 2010; Zhang et al. 2013). Voelckel and Baldwin (2004) found that transcriptional responses of Nicotiana attenuata plants to simultaneous attack by the sap-feeding insect Tupiocoris notatus and the chewing caterpillar Manduca sexta were different from those from either herbivore alone. Furthermore, simultaneous feeding by the aphid Macrosiphum euphorbiae and the caterpillar Spodoptera exigua on tomato plants resulted in a different pattern of gene expression compared to transcriptional responses induced by caterpillars or aphids alone (Rodriguez-Saona et al. 2010). In A. thaliana plants, feeding by the whitefly Bemisia tabaci suppressed the up-regulation of a large number of genes induced by $P$. xylostella caterpillars (Zhang et al. 2013). In contrast, we identified a larger number of DEGs in response to simultaneous feeding by P. xylostella caterpillars and B. brassicae aphids compared to caterpillars feeding alone. This may indicate that aphids and whiteflies, although both phloem feeders, interfere in 
Fig. 5 Heat map showing average $\log _{2}$-fold change ratios (measured relative to non-infested control samples) of genes expressed in A. thaliana at $48 \mathrm{~h}$ after single $P$. xylostella or dual $P$. xylostella and $B$. brassicae infestation. Plants were infested with either a low (LD) or high (HD) density of $B$. brassicae aphids. Hierarchical clustering (HCL) was performed using Spearman correlation with average linkage clustering. Red indicates up-regulated genes, while green shows down-regulated genes. Black represents no change in expression. Each row in the columns corresponds to a single gene. Cluster analysis is shown for clusters 2 and 6

a different way with caterpillar-induced defenses and cautions against generalizations based on feeding guild. Moreover, based on our data showing that herbivore density can also be an important factor modulating plant-mediated interactions, this may provide an additional explanation for the differences between results of the studies on the effects of aphids and whiteflies.

When comparing transcriptional responses of A. thaliana plants exposed to caterpillars feeding alone or to simultaneous feeding by caterpillars and aphids, different plant responses are induced. We observed up-regulation of several JA-responsive genes (PR4, HEL, VSP1, PDF1.2, TPSO4, CORI3, JR1) and genes involved in JA signal-transduction (JAZ5, JAZ9) in response to feeding by P. xylostella caterpillars (Online Resource 3). Several of these genes were also found to be up-regulated by $P$. xylostella infestation in a microarray study (Ehlting et al. 2008), which suggests that JA-mediated responses play an important role in plant defense against $P$. xylostella caterpillars (Zhang et al. 2013). In response to simultaneous aphid feeding, also genes related to metabolism of organic acids, fatty acids and oxylipins were up-regulated, compared to P. xylostella caterpillars feeding alone. Oxylipins are involved in plant responses to insect attack (Bostock 2005). For instance, oxylipin-related genes were up-regulated by $P$. xylostella feeding in Arabidopsis plants (Ehlting et al. 2008). Interestingly, also in response to aphid feeding, oxylipins are induced in A. thaliana and maize plants (Kusnierczyk et al. 2008; Tzin et al. 2015a). Therefore, oxylipins may be important for induced defenses in response to dual caterpillar and aphid infestation. Transcriptional interference between simultaneously feeding insect herbivores can lead to positive or negative effects on the performance of the herbivores. For example, in cabbage (Brassica oleracea) positive effects of $B$. brassicae aphid feeding on the performance of Pieris brassicae caterpillars were observed (Soler et al. 2012). In addition, caterpillars of the Monarch butterfly Danaus plexippus were positively affected on milkweed plants previously infested by oleander aphids Aphis nerii, whereas the aphids were negatively affected on milkweed plants previously infested by conspecific caterpillars (Ali et al. 2014).

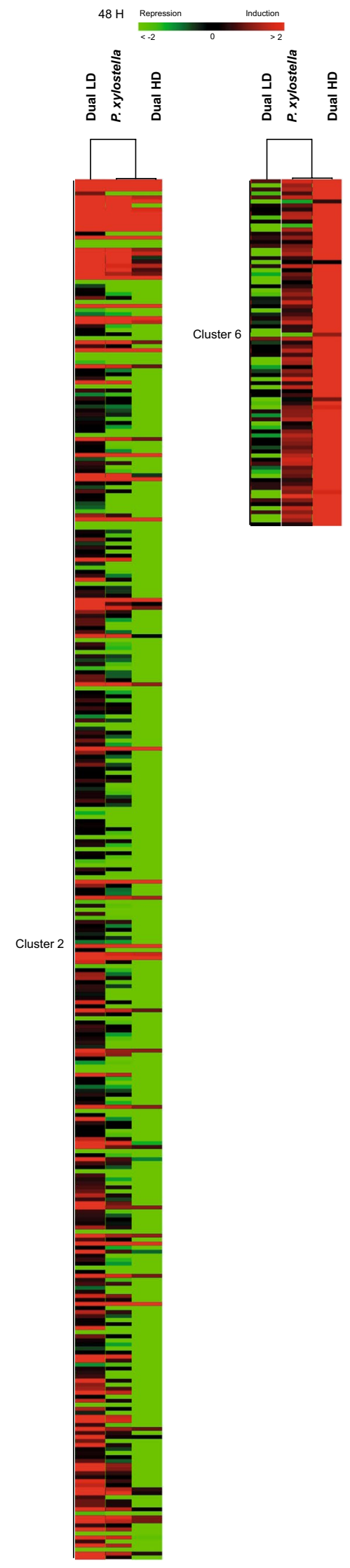




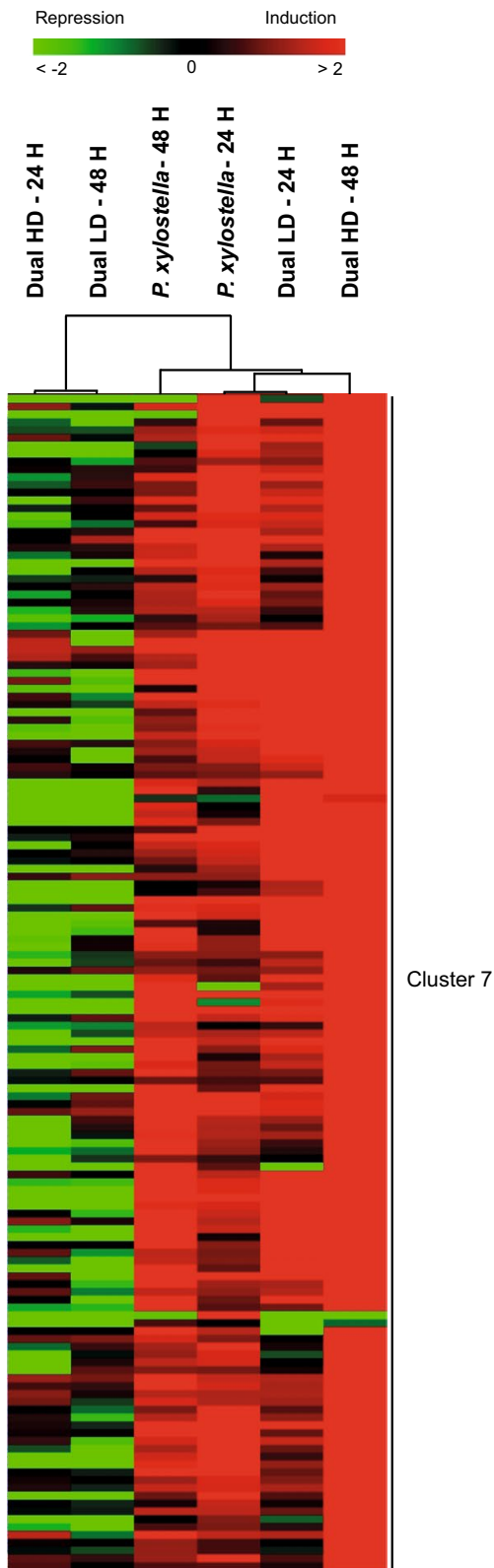

Fig. 6 Heat map showing average $\log _{2}$-fold change ratios (measured relative to non-infested control samples) of genes expressed in $A$. thaliana at 24 and $48 \mathrm{~h}$ after single $P$. xylostella or dual P. xylostella and $B$. brassicae infestation. Plants were infested with either a low (LD) or high (HD) density of B. brassicae aphids. Hierarchical clustering (HCL) was performed using Spearman correlation with average linkage clustering. Red indicates up-regulated genes, while green shows down-regulated genes. Black represents no change in expression. Each row in the columns corresponds to a single gene. Cluster analysis is shown for cluster 7

\section{Effect of insect density on transcriptional responses}

Induced plant responses to multiple herbivory can be influenced by the density of the attacking insects. For instance, interference by $B$. brassicae aphids with induced defenses against caterpillars depends on the density of the attacking aphids (Kroes et al. 2015; Ponzio et al. 2016). As a next step in the study of density-dependent interference of aphids with caterpillar-induced defenses, we studied the effect of different aphid densities on whole-genome transcriptional responses of $A$. thaliana to feeding by $P$. xylostella caterpillars.

We observed that transcriptional responses of A. thaliana to feeding by $P$. xylostella caterpillars were aphid density-dependent. There are differences in the nature of the differentially expressed genes when comparing plants with Dual LD and Dual HD treatments with caterpillar-infested plants after $48 \mathrm{~h}$ (Fig. 3). We found several WRKY transcription factor genes (WRKY33, WRKY4O and WRKY7O) only repressed in response to simultaneous aphid feeding at high density after $48 \mathrm{~h}$. WRKY proteins belong to a large family of transcriptional regulators in A. thaliana plants (Rushton et al. 2010) and play an important role in regulating plant responses to pathogens (Pandey and Somssich 2009). For example, the transcription factor WRKY33 mediates defense responses to the necrotrophic fungus Botrytis cinerea in A. thaliana (Birkenbihl et al. 2012). Furthermore, WRKY70 has a key role in regulating interactions between SA- and JA-mediated signalling pathways (Li et al. 2004; Pieterse et al. 2012). Overexpression of WRKY70 induced the expression of SA-mediated $P R$ genes, while it suppressed JA-responsive $P D F 1.2$ expression in A. thaliana plants ( $\mathrm{Li}$ et al. 2004). It has been suggested that by activating the SA signalling pathway, aphids could interfere with JA-dependent defenses against caterpillars (Stam et al. 2014). Differential expression of WRKY70 may underlie plant-mediated interactions between simultaneously attacking aphids and caterpillars. A negative correlation between SA-mediated WRKY70 expression and JA-dependent $M Y C 2$ expression in A. thaliana plants infested by both caterpillars and aphids was shown before and was also aphid-density dependent (Kroes et al. 2015). Expression of WRKY70 was down-regulated in Dual HD plants, which led to the induction of JA-mediated defenses (Kroes et al. 2015). By activating JA-dependent defenses in response to simultaneous feeding of caterpillars and aphids at high density, plants could increase defense against aphids and caterpillars.

Also WRKY40 is involved in the crosstalk between JA and SA signalling (Xu et al. 2006). Moreover, WRKY40 negatively regulates ABA-responsive gene expression (Chen et al. 2010). The plant hormone ABA is an important modulator of plant defense responses (Morkunas et al. 2011; Lee and Luan 2012). Here, we detected ABA-dependent genes that were differentially induced in response to Dual HD after $24 \mathrm{~h}$, compared to genes expressed in caterpillar-induced plants, but not in response to Dual LD (e.g. ABF1, PYR1, PLC1, SRK2D and AHK2). 
In addition, we found a group of genes (Cluster 5) that were more strongly up-regulated at $24 \mathrm{~h}$ in response to Dual HD compared to $P$. xylostella caterpillars feeding alone and to Dual LD (Fig. 4; Online Resource 5A). Cluster 5 contains the ABA receptors PYL4 and PYL5. These receptors inactivate plant PP2Cs, such as $A B I 1$ and $A B I 2$, which are known to suppress ABA signalling (Ma et al. 2009; Park et al. 2009). Recently, it was shown that aphids feeding on A. thaliana and the legume Medicago truncatula increase ABA content in the plants (Guo et al. 2016; Hillwig et al. 2016). Furthermore, M. persicae aphid population development was negatively affected on ABA-deficient mutants compared to wild-type A. thaliana plants (Kerchev et al. 2013; Hillwig et al. 2016). Thus, these results suggest that plant responses to simultaneous caterpillar and aphid feeding involves ABA signalling, which is dependent on aphid density and decreases defense responses against the attacking aphids. To support this, performance of aphids at different densities feeding simultaneously with caterpillars on ABA-deficient mutants should be studied.

Activation of plant defenses in response to herbivory is costly. It requires the diversion of resources away from plant growth (Huot et al. 2014) and herbivory suppresses photosynthesis (Zangerl et al. 2002; Voelckel and Baldwin 2004; Appel et al. 2014; Huot et al. 2014; Zhu et al. 2015). In response to P. xylostella feeding, or to Dual HD, we found a group of genes (Cluster 2) that were more strongly down-regulated after $48 \mathrm{~h}$ compared to Dual LD (Fig. 5; Online Resource 5B). This cluster contains genes associated with photosynthesis, which suggests that simultaneous feeding by caterpillars and aphids at a low or a high density has a different impact on the expression of photosynthesis-related genes. As a consequence, induction of plant defenses may be differentially affected in response to aphid feeding at low or high densities.

\section{The temporal dynamics of simultaneous herbivory}

Transcriptional responses to feeding by a single herbivore species are highly dynamic over time (Ehlting et al. 2008; Kusnierczyk et al. 2008; Appel et al. 2014; Tzin et al. 2015a; Davila Olivas et al. 2016). Transcriptional responses to caterpillars feeding alone and feeding by both caterpillars and aphids changed over time. Similar to the finding of Ehlting et al. (2008) that more genes are differentially expressed at early time points in response to P. xylostella feeding, we found that a higher number of DEGs was upregulated by $P$. xylostella caterpillar feeding after $24 \mathrm{~h}$ as compared to $P$. xylostella-induced DEGs after $48 \mathrm{~h}$. In addition, Voelckel and Baldwin (2004) showed that specific transcriptional changes to $M$. sexta caterpillar infestation on tobacco plants occur after $24 \mathrm{~h}$ but these disappeared after 5 days of feeding.
Our cluster analysis showed that time-dependent transcripts in response to dual infestation were affected by the density of the attacking aphids. In response to Dual LD during $48 \mathrm{~h}$, a similar transcriptional pattern was expressed as that found in response to Dual HD during $24 \mathrm{~h}$. This indicates that insects attacking at a high density cause an acceleration in plant responses compared to insects attacking at a low density. Furthermore, we found that plant responses to Dual HD during $48 \mathrm{~h}$ clustered together with responses found after $24 \mathrm{~h}$ of Dual LD. Interestingly, many of the upregulated genes from Cluster 7 in response to the two aphid densities at both time points are known to be involved in plant defenses (e.g. LCR17, LCR29, FRK1, PROPEP3, MYB78, LCR37, MLP329 and different cytochrome P450 genes) (Fig. 6; Online Resource 5C). For example, MYB78 belongs to the R2R3-type $M Y B$ genes which are involved in plant defense responses (Stracke et al. 2001; Dubos et al. 2010). In A. thaliana plants, MYB78 was shown to play a role in the defense response regulated by JA against Botrytis cinerea and Alternaria brassicicola infection (Mengiste et al. 2003). Another example is PROPEP3 which encodes precursor proteins that, upon perception by two closely related receptor kinases, PEPR1 and PEPR2, activate plant defense (Bartels et al. 2013). Upon feeding by Spodoptera littoralis caterpillars, PROPEP3 is up-regulated in A. thaliana plants (Klauser et al. 2015). Furthermore, the performance of $S$. littoralis was positively affected when feeding on pepr1 pepr 2 double mutants (Klauser et al. 2015). Also, FRK1 (flg22-induced receptor-like kinase 1) expression was shown to be up-regulated to a significantly higher level by $B$. brassicae-derived elicitors compared to waterinfiltrated A. thaliana leaves (Prince et al. 2014). In addition, SA signalling is involved in the regulation of $F R K 1$ expression (Yi et al. 2014). This may indicate that $F R K 1$ is involved in defense signalling against $B$. brassicae feeding.

\section{Conclusion}

We determined if aphids interfere with transcriptional responses of $A$. thaliana plants to $P$. xylostella caterpillars and whether this interference was dependent on aphid density. We show that the density of simultaneously feeding aphids has a differential effect on transcriptional responses in A. thaliana plants attacked by $P$. xylostella caterpillars, i.e. high aphid density has a stronger effect on caterpillar-induced responses than a low aphid density. In addition, transcriptomic responses are dynamic over time. In response to $P$. xylostella feeding alone, transcriptional changes were strongest after $24 \mathrm{~h}$ and mainly involved JA-responsive genes. When comparing gene expression patterns between time points and insect treatments, transcriptional patterns were similar between dual infestation 
at low density during $48 \mathrm{~h}$ and dual infestation at high density during $24 \mathrm{~h}$. This indicates that insects attacking at a high density cause an acceleration in plant responses compared to insects attacking at low density. Furthermore, response to dual infestation at low density during $24 \mathrm{~h}$ and dual infestation at high density during $48 \mathrm{~h}$ mainly involved plant defense genes.

This study highlights the importance of addressing insect density and temporal dynamics to understand plant responses to dual or single insect attack. Mutant analysis studies are needed to confirm the function of genes involved in plant responses to single or dual insect attack.

Acknowledgments We thank Léon Westerd, Frans van Aggelen and André Gidding for culturing the insects; Rieta Gols for assistance with the multivariate data analysis; Sander Weerheim for help with sample collection.

Author contribution statement $\mathrm{MD}, \mathrm{CB}, \mathrm{JvL}$ and $\mathrm{AK}$ designed the research. AK performed the research. AK and MCU analyzed data. $\mathrm{AK}, \mathrm{JvL}$ and MD wrote the paper with input from CB, MCU and SM.

\section{Compliance with ethical standards}

Funding This work was supported by a TOP GO grant (Grant No. 854.10.010 to MD) from The Netherlands Organization for Scientific Research (NWO). CB was supported by the Dutch Technology Foundation STW, part of NWO (VENI Grant No. 13087).

Open Access This article is distributed under the terms of the Creative Commons Attribution 4.0 International License (http://creativecommons.org/licenses/by/4.0/), which permits unrestricted use, distribution, and reproduction in any medium, provided you give appropriate credit to the original author(s) and the source, provide a link to the Creative Commons license, and indicate if changes were made.

\section{References}

Ali JG, Agrawal AA, Fox C (2014) Asymmetry of plant-mediated interactions between specialist aphids and caterpillars on two milkweeds. Funct Ecol 28:1404-1412

Anderson JP, Badruzsaufari E, Schenk PM, Manners JM, Desmond OJ, Ehlert C, Maclean DJ, Ebert PR, Kazan K (2004) Antagonistic interaction between abscisic acid and jasmonate-ethylene signaling pathways modulates defense gene expression and disease resistance in Arabidopsis. Plant Cell 16:3460-3479

Appel HM, Fescemyer H, Ehlting J, Weston D, Rehrig E, Joshi T, Xu D, Bohlmann J, Schultz J (2014) Transcriptional responses of Arabidopsis thaliana to chewing and sucking insect herbivores. Front Plant Sci 5:565

Barah P, Winge P, Kusnierczyk A, Tran DH, Bones AM (2013) Molecular signatures in Arabidopsis thaliana in response to insect attack and bacterial infection. PLoS One 8:e58987

Bartels S, Lori M, Mbengue M, Van Verk M, Klauser D, Hander T, Boni R, Robatzek S, Boller T (2013) The family of AtPeps and their precursors in Arabidopsis: differential expression and localization but similar induction of pattern-triggered immune responses. J Exp Bot 64:5309-5321
Bidart-Bouzat MG, Kliebenstein D (2011) An ecological genomic approach challenging the paradigm of differential plant responses to specialist versus generalist insect herbivores. Oecologia 167:677-689

Birkenbihl RP, Diezel C, Somssich IE (2012) Arabidopsis WRKY33 is a key transcriptional regulator of hormonal and metabolic responses toward Botrytis cinerea infection. Plant Physiol 159:266-285

Bostock RM (2005) Signal crosstalk and induced resistance: straddling the line between cost and benefit. Annu Rev Phytopathol 43:545-580

Broekgaarden C, Caarls L, Vos IA, Pieterse CMJ, Van Wees SCM (2015) Ethylene: traffic controller on hormonal crossroads to defense. Plant Physiol 169:2371-2379

Caarls L, Pieterse CMJ, Van Wees SCM (2015) How salicylic acid takes transcriptional control over jasmonic acid signaling. Front Plant Sci 6:170

Chen H, Lai Z, Shi J, Xiao Y, Chen Z, Xu X (2010) Roles of Arabidopsis WRKY18, WRKY40 and WRKY60 transcription factors in plant responses to abscisic acid and abiotic stress. BMC Plant Biol 10:281

Coolen S, Proietti S, Hickman R, Davila Olivas NH, Huang P, Van Verk M, Van Pelt J, Wittenberg A, De Vos M, Prins M, van Loon JJA, Aarts MGM, Dicke M, Pieterse CMJ, van Wees SCM (2016) Transcriptome dynamics of Arabidopsis during sequential biotic and abiotic stresses. Plant J 86:249-267

Couldridge C, Newbury HJ, Ford-Lloyd B, Bale J, Pritchard J (2007) Exploring plant responses to aphid feeding using a full Arabidopsis microarray reveals a small number of genes with significantly altered expression. Bull Entomol Res 97:523-532

Davila Olivas NH, Coolen S, Huang P, Severing E, Van Verk MC, Hickman R, Wittenberg AHJ, De Vos M, Prins M, Van Loon JJA, Aarts MGM, Van Wees SCM, Pieterse CMJ, Dicke M (2016) Effect of prior drought and pathogen stress on Arabidopsis transcriptome changes to caterpillars herbivory. New Phytol 210:1344-1356

Derksen H, Rampitsch C, Daayf F (2013) Signaling cross-talk in plant disease resistance. Plant Sci 207:79-87

De Vos M, Van Oosten VR, Van Poecke RMP, Van Pelt JA, Pozo MJ, Mueller MJ, Buchala AJ, Métraux J-P, Van Loon JC, Dicke M, Pieterse CMJ (2005) Signal signature and transcriptome changes of Arabidopsis during pathogen and insect attack. Mol Plant Microbe Interact J 18:923-937

De Vos M, Kim JH, Jander G (2007) Biochemistry and molecular biology of Arabidopsis-aphid interactions. BioEssays 29:871-883

Dombrecht B, Xue GP, Sprague SJ, Kirkegaard JA, Ross JJ, Reid JB, Fitt GP, Sewelam N, Schenk PM, Manners JM, Kazan K (2007) MYC2 differentially modulates diverse jasmonate-dependent functions in Arabidopsis. Plant Cell 19:2225-2245

Dubos C, Stracke R, Grotewold E, Weisshaar B, Martin C, Lepiniec L (2010) MYB transcription factors in Arabidopsis. Trends Plant Sci 15:573-581

Ehlting J, Chowrira SG, Mattheus N, Aeschliman DS, Arimura G, Bohlmann J (2008) Comparative transcriptome analysis of Arabidopsis thaliana infested by diamond back moth (Plutella xylostella) larvae reveals signatures of stress response, secondary metabolism, and signalling. BMC Genom 9:154

Erb M, Meldau S, Howe GA (2012) Role of phytohormones in insectspecific plant reactions. Trends Plant Sci 17:250-259

Eriksson L, Byrne T, Johansson E, Trygg J, Vikström C (2013) Multiand megavariate data analysis: basic principles and applications, 3rd edn. Umetrics Academy, Malmö

Guo H, Sun Y, Peng X, Wang Q, Harris M, Ge F (2016) Up-regulation of abscisic acid signaling pathway facilitates aphid xylem 
absorption and osmoregulation under drought stress. J Exp Bot 67:681-693

Halitschke R, Baldwin IT (2003) Antisense LOX expression increases herbivore performance by decreasing defense responses and inhibiting growth-related transcriptional reorganization in Nicotiana attenuata. Plant J 36:794-807

Herde M, Gartner K, Kollner TG, Fode B, Boland W, Gershenzon J, Gatz C, Tholl D (2008) Identification and regulation of TPS04/ GES, an Arabidopsis geranyllinalool synthase catalyzing the first step in the formation of the insect-induced volatile C16-homoterpene TMTT. Plant Cell 20:1152-1168

Hillwig MS, Chiozza M, Casteel CL, Lau ST, Hohenstein J, Hernandez E, Jander G, MacIntosh GC (2016) Abscisic acid deficiency increases defence responses against Myzus persicae in Arabidopsis. Mol Plant Pathol 17:225-235

Hong GJ, Xue XY, Mao YB, Wang LJ, Chen XY (2012) Arabidopsis MYC2 interacts with DELLA proteins in regulating sesquiterpene synthase gene expression. Plant Cell 24:2635-2648

Huang DW, Sherman BT, Lempicki RA (2009) Systematic and integrative analysis of large gene lists using DAVID bioinformatics resources. Nat Protoc 4:44-57

Huot B, Yao J, Montgomery BL, He SY (2014) Growth-defense tradeoffs in plants: a balancing act to optimize fitness. Mol Plant 7:1267-1287

Kazan K, Manners JM (2013) MYC2: the master in action. Mol Plant 6:686-703

Kerchev PI, Karpinska B, Morris JA, Hussain A, Verrall SR, Hedley PE, Fenton B, Foyer CH, Hancock RD (2013) Vitamin C and the abscisic acid-insensitive 4 transcription factor are important determinants of aphid resistance in Arabidopsis. Antioxid Redox Signal 18:2091-2105

Kessler A, Baldwin IT (2002) Plant responses to insect herbivory: the emerging molecular analysis. Annu Rev Plant Biol 53:299-328

Klauser D, Desurmont GA, Glauser G, Vallat A, Flury P, Boller T, Turlings TCJ, Bartels S (2015) The Arabidopsis Pep-PEPR system is induced by herbivore feeding and contributes to JA-mediated plant defence against herbivory. J Exp Bot 66:5327-5336

Koo AJ, Howe GA (2009) The wound hormone jasmonate. Phytochemistry 70:1571-1580

Kroes A, Van Loon JJA, Dicke M (2015) Density-dependent interference of aphids with caterpillar-induced defenses in Arabidopsis: involvement of phytohormones and transcription factors. Plant Cell Physiol 56:98-106

Kusnierczyk A, Winge P, Jorstad TS, Troczynska J, Rossiter JT, Bones AM (2008) Towards global understanding of plant defence against aphids-timing and dynamics of early Arabidopsis defence responses to cabbage aphid (Brevicoryne brassicae) attack. Plant Cell Environ 31:1097-1115

Lee SC, Luan S (2012) ABA signal transduction at the crossroad of biotic and abiotic stress responses. Plant Cell Environ 35:53-60

Li J, Brader G, Palva ET (2004) The WRKY70 transcription factor: a node of convergence for jasmonate-mediated and salicylatemediated signals in plant defense. Plant Cell 16:319-331

Li Y, Dicke M, Harvey JA, Gols R (2014) Intra-specific variation in wild Brassica oleracea for aphid-induced plant responses and consequences for caterpillar-parasitoid interactions. Oecologia 174:853-862

Livak KJ, Schmittgen TD (2001) Analysis of relative gene expression data using real-time quantitative PCR and the 2-Delta Delta CT Method. Methods 25:402-408

Lorenzo O, Solano R (2005) Molecular players regulating the jasmonate signalling network. Curr Opin Plant Biol 8:532-540

Lorenzo O, Piqueras R, Sánchez-Serrano JJ, Solano R (2003) ETHYLENE RESPONSE FACTOR1 integrates signals from ethylene and jasmonate pathways in plant defense. Plant Cell 15:165-178
Lorenzo O, Chico JM, Sanchez-Serrano JJ, Solano R (2004) JASMONATE-INSENSITIVE1 encodes a MYC transcription factor essential to discriminate between different jasmonate-regulated defense responses in Arabidopsis. Plant Cell 16:1938-1950

Ma Y, Szostkiewicz I, Korte A, Moes D, Yang Y, Christmann A, Grill E (2009) Regulators of PP2C phosphatase activity function as abscisic acid sensors. Science 324:1064-1068

Memelink J (2009) Regulation of gene expression by jasmonate hormones. Phytochemistry 70:1560-1570

Mengiste T, Chen X, Salmeron J, Dietrich R (2003) The BOTRYTIS SUSCEPTIBLE1 gene encodes an R2R3MYB transcription factor protein that is required for biotic and abiotic stress responses in Arabidopsis. Plant Cell 15:2551-2565

Mithofer A, Boland W (2012) Plant defense against herbivores: chemical aspects. Annu Rev Plant Biol 63:431-450

Moran PJ, Cheng Y, Cassell JL, Thompson GA (2002) Gene expression profiling of Arabidopsis thaliana in compatible plant-aphid interactions. Arch Insect Biochem Physiol 51:182-203

Morkunas I, Mai VC, Gabryś B (2011) Phytohormonal signaling in plant responses to aphid feeding. Acta Physiologiae Plant 33:2057-2073

Onkokesung N, Reichelt M, Van Doorn A, Schuurink R, Dicke M (2016) Differential costs of two distinct resistance mechanisms induced by different herbivore species in Arabidopsis thaliana. Plant Physiol 170:891-906

Pandey SP, Somssich IE (2009) The role of WRKY transcription factors in plant immunity. Plant Physiol 150:1648-1655

Park SY, Fung P, Nishimura N, Jensen DR, Fujii H, Zhao Y, Lumba S, Santiago J, Rodrigues A, Chow TF, Alfred SE, Bonetta D, Finkelstein R, Provart NJ, Desveaux D, Rodriguez PL, McCourt P, Zhu JK, Schroeder JI, Volkman BF, Cutler SR (2009) Abscisic acid inhibits type $2 \mathrm{C}$ protein phosphatases via the PYR/PYL family of START proteins. Science 324:1068-1071

Pieterse CMJ, Van der Does D, Zamioudis C, Leon-Reyes A, Van Wees SCM (2012) Hormonal modulation of plant immunity. Annu Rev Cell Dev Biol 28:489-521

Ponzio C, Cascone P, Cusumano A, Weldegergis BT, Fatouros NE, Guerrieri E, Dicke M, Gols R (2016) Volatile-mediated foraging behaviour of three parasitoid species under conditions of dual insect herbivore attack. Anim Behav 111:197-206

Prince DC, Drurey C, Zipfel C, Hogenhout SA (2014) The leucinerich repeat receptor-like kinase BRASSINOSTEROID INSENSITIVE1-ASSOCIATED KINASE1 and the cytochrome P450 PHYTOALEXIN DEFICIENT3 contribute to innate immunity to aphids in Arabidopsis. Plant Physiol 164:2207-2219

Rehrig EM, Appel HM, Jones AD, Schultz JC (2014) Roles for jasmonate- and ethylene-induced transcription factors in the ability of Arabidopsis to respond differentially to damage caused by two insect herbivores. Front Plant Sci 5:407

Remans T, Smeets K, Opdenakker K, Mathijsen D, Vangronsveld J, Cuypers A (2008) Normalisation of real-time RT-PCR gene expression measurements in Arabidopsis thaliana exposed to increased metal concentrations. Planta 227:1343-1349

Robert-Seilaniantz A, MacLean D, Jikumaru Y, Hill L, Yamaguchi S, Kamiya Y, Jones JDG (2011) The microRNA miR393 re-directs secondary metabolite biosynthesis away from camalexin and towards glucosinolates. Plant J 67:218-231

Rodriguez-Saona CR, Musser RO, Vogel H, Hum-Musser SM, Thaler JS (2010) Molecular, biochemical, and organismal analyses of tomato plants simultaneously attacked by herbivores from two feeding guilds. J Chem Ecol 36:1043-1057

Rushton PJ, Somssich IE, Ringler P, Shen QJ (2010) WRKY transcription factors. Trends Plant Sci 15:247-258

Saeed A, Sharov V, White J, Li J, Liang W, Bhagabati N, Braisted J, Klapa M, Currier T, Thiagarajan M, Sturn A, Snuffin M, Rezantsev A, Popov D, Ryltsov A, Kostukovich E, Borisovsky I, Liu Z, 
Vinsavich A, Trush V, Quackenbush J (2003) TM4: a free, opensource system for microarray data management and analysis. Biotechniques 2:374-378

Saeed A, Bhagabati N, Braisted J, Liang W, Sharov V, Howe EA, Li J, Thiagarajan M, White JA, Quackenbush J (2006) TM4 microarray software suite. Methods Enzymol 411:134-193

Snoeren TAL, Kappers IF, Broekgaarden C, Mumm R, Dicke M, Bouwmeester HJ (2010) Natural variation in herbivore-induced volatiles in Arabidopsis thaliana. J Exp Bot 61:3041-3056

Soler R, Badenes-Pérez FR, Broekgaarden C, Zheng S-J, David A, Boland W, Dicke M (2012) Plant-mediated facilitation between a leaf-feeding and a phloem-feeding insect in a brassicaceous plant: from insect performance to gene transcription. Funct Ecol 26:156-166

Stam JM, Kroes A, Li Y, Gols R, Van Loon JJA, Poelman EH, Dicke M (2014) Plant interactions with multiple insect herbivores: from community to genes. Annu Rev Plant Biol 65:689-713

Stewart SA, Hodge S, Bennett M, Mansfield JW, Powell G (2016) Aphid induction of phytohormones in Medicago truncatula is dependent upon time post-infestation, aphid density and the genotypes of both plant and insect. Arthropod Plant Interact 10:41-53

Stotz HU, Pittendrigh BR, Kroymann J, Weniger K, Fritsche J, Bauke A, Mitchell-Olds T (2000) Induced plant defense responses against chewing insects. Ethylene signaling reduces resistance of Arabidopsis against Egyptian Cotton worm but not Diamondback moth. Plant Physiol 124:1007-1017

Stracke R, Werber M, Weisshaar B (2001) The R2R3-MYB gene family in Arabidopsis thaliana. Curr Opin Plant Biol 4:447-456

Thaler JS, Farag MA, Paré PW, Dicke M (2002) Jasmonate-deficient plants have reduced direct and indirect defences against herbivores. Ecol Lett 5:764-774

Thines B, Katsir L, Melotto M, Niu Y, Mandaokar A, Liu G, Nomura K, He SY, Howe GA, Browse J (2007) JAZ repressor proteins are targets of the $\mathrm{SCF}(\mathrm{COI} 1)$ complex during jasmonate signalling. Nature 448:661-665

Turner JG, Ellis C, Devoto A (2002) The jasmonate signal pathway. Plant Cell 14:S153-S164

Tzin V, Fernandez-Pozo N, Richter A, Schmelz EA, Schoettner M, Schafer M, Ahern KR, Meihls LN, Kaur H, Huffaker A, Mori
N, Degenhardt J, Mueller LA, Jander G (2015a) Dynamic maize responses to aphid feeding are revealed by a time series of transcriptomic and metabolomic assays. Plant Physiol 169:1727-1743

Tzin V, Lindsay PL, Christensen SA, Meihls LN, Blue LB, Jander G (2015b) Genetic mapping shows intraspecific variation and transgressive segregation for caterpillar-induced aphid resistance in maize. Mol Ecol 24:5739-5750

Verhage A, Vlaardingerbroek I, Raaymakers C, Van Dam NM, Dicke M, Van Wees SCM, Pieterse CMJ (2011) Rewiring of the jasmonate signaling pathway in Arabidopsis during insect herbivory. Front Plant Sci 2:47

Voelckel C, Baldwin IT (2004) Herbivore-induced plant vaccination. Part II. Array-studies reveal the transience of herbivore-specific transcriptional imprints and a distinct imprint from stress combinations. Plant J 38:650-663

Xu X, Chen C, Fan B, Chen Z (2006) Physical and functional interactions between pathogen-induced Arabidopsis WRKY18, WRKY40, and WRKY60 transcription factors. Plant Cell 18:1310-1326

Yi SY, Shirasu K, Moon JS, Lee SG, Kwon SY (2014) The activated SA and JA signaling pathways have an influence on flg22-triggered oxidative burst and callose deposition. PLoS One 9:e88951

Zangerl AR, Hamilton JG, Miller TJ, Crofts AR, Oxborough K, Berenbaum MR, de Lucia EH (2002) Impact of folivory on photosynthesis is greater than the sum of its holes. Proc Natl Acad Sci 99:1088-1091

Zhang PJ, Zheng SJ, Van Loon JJA, Boland W, David A, Mumm R, Dicke M (2009) Whiteflies interfere with indirect plant defense against spider mites in Lima bean. Proc Natl Acad Sci 106:21202-21207

Zhang PJ, Broekgaarden C, Zheng SJ, Snoeren TAL, Van Loon JJA, Gols R, Dicke M (2013) Jasmonate and ethylene signaling mediate whitefly-induced interference with indirect plant defense in Arabidopsis thaliana. New Phytol 197:1291-1299

Zhu F, Broekgaarden C, Weldegergis BT, Harvey JA, Vosman B, Dicke M, Poelman EH (2015) Parasitism overrides herbivore identity allowing hyperparasitoids to locate their parasitoid host using herbivore-induced plant volatiles. Mol Ecol 24:2886-2899 